\begin{tabular}{|c|c|}
\hline Title & Effect of low salinity on the survival and development of Japanese common squid Todarodes pacificus hatchling \\
\hline Author(s) & Furukawa, Hiroko; Sakurai, Y asunori \\
\hline Citation & $\begin{array}{l}\text { Fisheries Science, } 74(2), 458.460 \\
\text { https://doi.org/10.1111j.1444.2906.2008.01546.x }\end{array}$ \\
\hline Issue Date & $2008-04$ \\
\hline Doc URL & http:/hdl.handle.net/2115/39551 \\
\hline Rights & ○ 2008 公益社団法人日本水産学会; @ 2008 The Japanese Society of Fisheries Science \\
\hline Type & article \\
\hline File Information & sakurai_FS74-2.pdf \\
\hline
\end{tabular}

Instructions for use 


\title{
Effect of low salinity on the survival and development of Japanese common squid Todarodes pacificus hatchling
}

\author{
HIROKO FURUKAWA AND YASUNORI SAKURAI* \\ Graduate School of Fisheries Sciences, Hokkaido University, Hakodate, Hokkaido 041-8611, \\ Japan
}

KEY WORDS: development, hatchling, Japanese common squid, salinity, survival, Todarodes pacificus.

The ommastrephid squid Todarodes pacificus grows fast and has short life span. ${ }^{1}$ In such shortlived species, reproductive and recruitment success depend largely on the physical and biological environments at the spawning and nursery grounds, ${ }^{2}$ and Sakurai et al. ${ }^{2,3}$ suggested that the reproductive success of $T$. pacificus is affected by temperature. The main spawning grounds of T. pacificus extend from the southern Sea of Japan to the East China Sea, ${ }^{1,3}$ in an area where the salinity of surface waters is often low. ${ }^{4}$ A recent study reported that the low salinity water $(<27.0 \mathrm{psu})$ distributes in Tsushima Strait. ${ }^{4}$ In a hypothesis of T. pacificus reproduction, spawning is assumed to occur above the continental shelf and slope around Japan, and egg masses stay near the pycnocline. ${ }^{2}$ After hatching, hatchlings swim to the surface. ${ }^{5}$ Most T. pacificus hatchlings occur at $0-50 \mathrm{~m}$ depth, ${ }^{6}$ which suggests that salinity might also affect the reproductive success of this species. The present study examines the effect of low salinity on the survival and development of T. pacificus hatchlings.

Fertilized eggs of T. pacificus were obtained by artificial fertilization using the method described by Sakurai et al. ${ }^{7}$ Eggs were divided into groups of $67.5( \pm 29.43 \mathrm{SD})$ per Petri dish filled with filter-sterilized, aerated sea water. The eggs were

${ }^{*}$ Corresponding author: Tel: 81-138-40-8861. Fax: 81-138-40-8861. Email: sakurai@fish.hokudai.ac.jp Received 16 June 2006. Accepted 4 December 2006. maintained in incubators under a constant photoperiod $\left(12 \mathrm{~h}\right.$ light $/ 12 \mathrm{~h}$ dark), temperature $\left(20^{\circ} \mathrm{C}\right)$ and salinity (33.45 psu). The sea water in each Petri dish was changed twice daily. Six hours after hatching, hatchlings that developed normally (i.e. as described in Watanabe et $a l^{8}{ }^{8}$ ) were divided into groups of 20 per Petri dish and immersed in one of five salinity treatments: $33.45,31.47,29.57,27.58$, and 23.75 psu. The four less saline treatments were made by diluting 33.45 psu sea water with fresh water. All sea water used was filter-sterilized and aerated, and the treatments were maintained under similar conditions (except for the salinity) as during the embryonic period. In each treatment, six replicate Petri dishes were used.

Every $4 \mathrm{~h}$, live hatchlings were classified as either 'normal' (similar to those described by Watanabe et al. ${ }^{8}$ ) or 'deformed' (Fig. 1), each group was counted and dead hatchlings were removed from the Petri dishes. 'Dead hatchlings' were defined as individuals that were not moving their mantles or the other part of their body. The development stage of each normal hatchling was determined based on the stage descriptions in Watanabe et al. ${ }^{8}$ and hatchlings were observed to see if they could swim. Each treatment continued until most of the hatchlings reached development stage 32 , which digestive gland becomes larger and the proboscis streches. ${ }^{8}$

Survival rates $108 \mathrm{~h}$ after the start of treatments were high (>90\%) in the three highest salinities, but dropped to $77.5 \%$ at $27.58 \mathrm{psu}$ and $0.8 \%$ at 23.75 psu. Significantly fewer embryos developed 

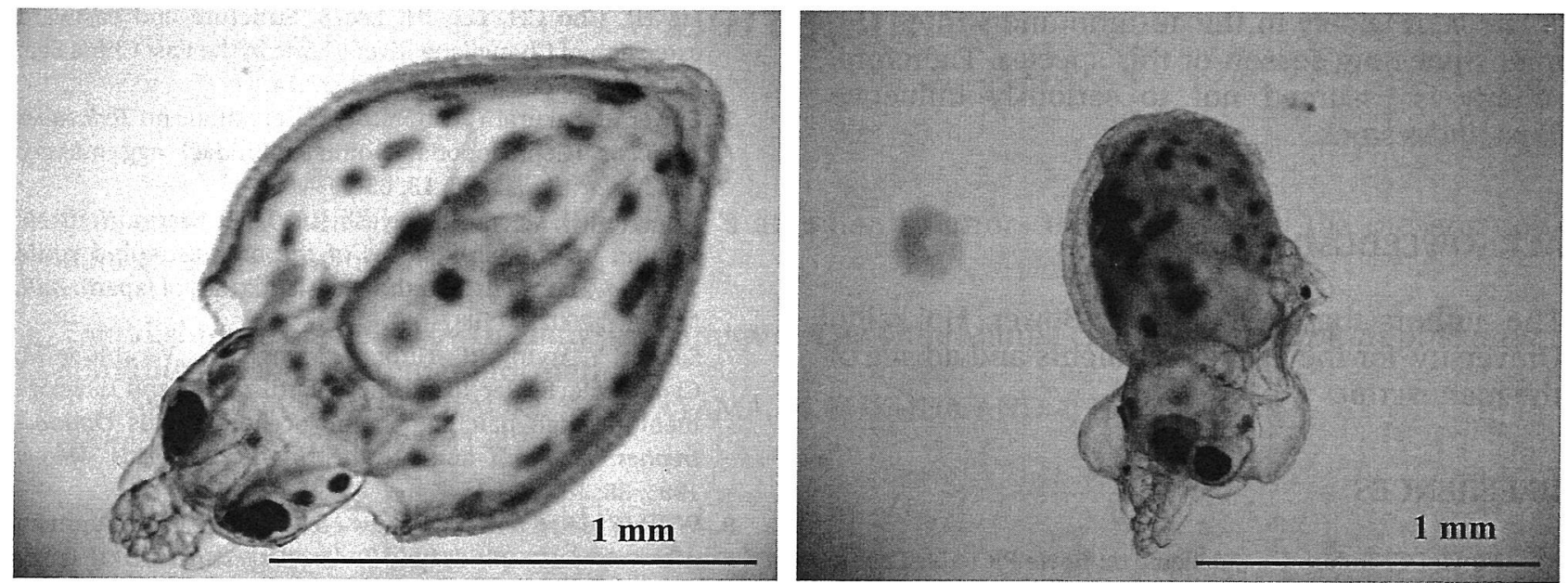

Fig. 1 Normal hatchling (as described by Watanabe et al. ${ }^{8}$ ) (left) and deformed hatchling (right) of the Japanese common squid Todarodes pacificus.

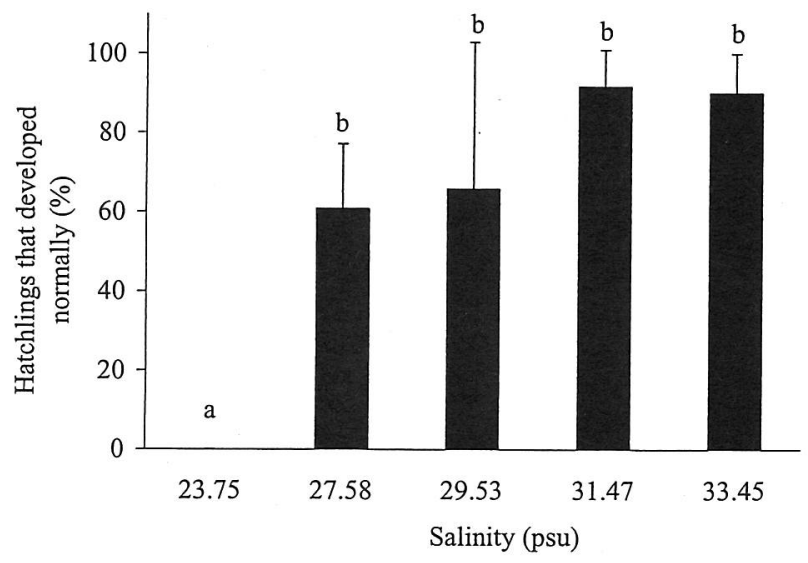

Fig. 2 Percentage of Todarodes pacificus hatchlings that developed normally at different salinities. Error bars indicate standard deviation. Values with the same letter did not differ significantly (Sheffe's test, $P>0.05$ ).

normally to stage 32 at salinity 23.75 psu than at the higher salinities $(P<0.01$, Sheffe's test, Fig. 2). The developmental rates of normal hatchlings were similar between treatments; most reached stage 32 by $108 \mathrm{~h}$ in all treatments.

None of the deformed hatchlings could swim, which suggests that they do not survive long. Therefore, the survival rate of normal hatchlings, by eliminating all dead and deformed hatchlings, was calculated. At the end of the experiment, the survival rates of normal hatchlings were $87.5,87.5$, $69.2,64.2$ and $0 \%$ at $33.45,31.47,29.53,27.58$ and 23.75 psu, respectively (Fig. 3).

Normal hatchlings in the 33.45 and $31.47 \mathrm{psu}$ treatments could swim, but those in the 29.53 and $27.58 \mathrm{psu}$ treatments, while capable of moving

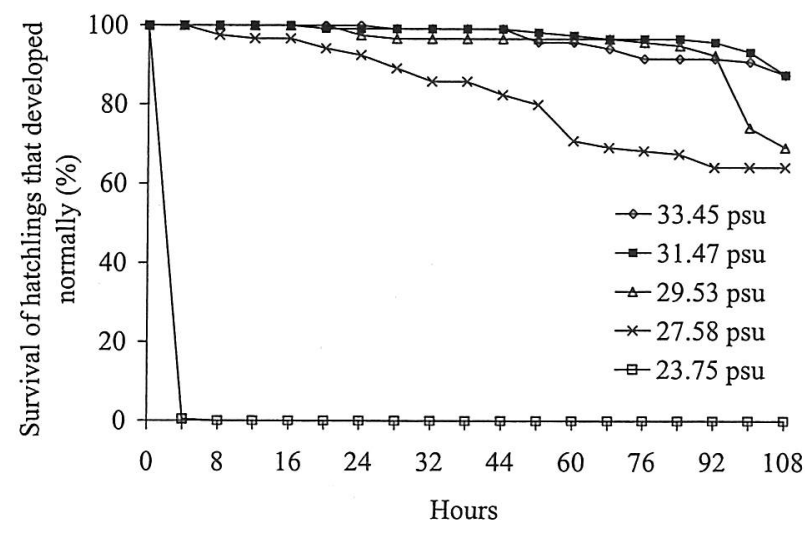

Fig. 3 Survival of normally developed Todarodes pacificus hatchlings at different salinities. Deformed hatchlings were counted as dead hatchlings.

their mantles, could not swim. This suggests that T. pacificus hatchlings require salinity levels above 29.53 psu to survive.

Some studies reported the effect of low salinity in some neritic species. Embryonic survival of Loligo gahi was high, within 25.4-32.8 psu. $^{9}$ In Sepia officinallis, the highest hatching percentages were found above $29.8 \mathrm{psu}$, and some embryos hatched at 26.5 psu. $^{10}$ The present study shows that hatchlings of $T$. pacificus survival under slightly higher salinity levels compared with Loligo gahi and Sepia officinallis.

Low salinity water often covers from the East China Sea to Tsushima Strait, which is the spawning area of $T$. pacificus. ${ }^{2,4}$ However, the peak of low salinity water distribution occurs in summer. ${ }^{4}$ It is supposed to be rare that lower salinity water than 29.53 psu covered with the spawning area of 
T. pacificus widely in the autumn and winter, the main spawning season of this species. Therefore, salinity is assumed not to seriously influence T. pacificus stock.

\section{ACKNOWLEDGMENTS}

The authors thank Dr John R. Bower, Hokkaido University, for the useful comments and advice of the manuscript.

\section{REFERENCES}

1. Okutani T. Todarodes pacificus. In: Boyle PR (ed.). Cephalopod Life Cycles, Vol. 1. Academic Press, London. 1983; 201214.

2. Sakurai Y, Kiyofuji H, Saitoh S, Goto T, Hiyama Y. Changes in inferred spawning areas of Todarodes pacificus (Cephalopoda: Ommastrephidae) due to changing environmental conditions. ICES J. Mar. Sci. 2000; 57: 24-30.

3. Sakurai Y, Bower JR, Nakamura Y, Yamamoto S, Watanabe K. Effects of temperature on development and survival of Japanese common squid (Todarodes pacificus) paralarvae. Am. Malac. Bull. 1996; 13: 89-95.
4. Lie HJ, Cho $\mathrm{CH}$, Lee JH, Lee S. Structure and eastward extension of Changjiang River plume in the East China Sea. J. Geophys. Res. 2003; 108: 22.1-22.14.

5. Bower JR, Sakurai Y. Laboratory observations on Todarodes pacificus (Cephalopoda: Ommastrephidae) egg masses. Am. Malac. Bull. 1996; 13: 65-71.

6. Yamamoto J, Masuda S, Miyashita K, Uji R, Sakurai Y. Investigation on the early stages of the ommastrephid squid Todarodes pacificus near the Oki Islands (Sea of Japan). Bull. Mar. Sci. 2002; 71: 987-992.

7. Sakurai $Y$, Young RE, Hirota J, Mangold $K$, Vecchione $M$, Clarke MR, Bower IR. Artificial fertilization and development through hatching in the oceanic squids Ommastrephes bartramii and Stenoteuthis oualaniensis. Veliger 1995; 38: 185-191.

8. Watanabe K, Sakurai Y, Segawa S, Okutani T. Development of the ommastrephid squid Todarodes pacificus, from fertilized egg to rhynchoteuthion paralarva. Am. Malac. Bull. 1996; 12: 73-88.

9. Cinti A, Barón PJ, Rivas AL. The effects of environmental factors on the embryonic survival of the Patagonian squid Loligo gahi. J. Exp. Mar. Biol. Ecol. 2004; 313: 225240.

10. Paulij WP, Bogaards RH, Denucé JM. Influence of salinity on embryonic development and the distribution of Sepia officinalis in the Delta Area (South Western part of The Netherlands). Mar. Boil. 1990; 107: 17-23. 